\title{
Representaciones, significados y sentidos al degustar una taza de café en la gran pantalla
}

\author{
Sandro Alberto Díaz Boada* \\ Universidad Santo Tomás, Seccional Bucaramanga, Colombia \\ Catalina Silva Arias \\ Universidad Cooperativa de Colombia, Colombia
}

Recibido: 8 de enero 2019; aceptado: 12 de marzo 2020

\begin{abstract}
Resumen
El presente artículo surge del hechizo de la combinación entre el café y el séptimo arte, se intenta aquí cavilar sobre las diferentes representaciones, significados y sentidos que surgen tras observar a la misteriosa bebida oscura proyectada en la gran pantalla. Para poder aspirar el profundo aroma del café se revisa con detenimiento un largometraje mítico de Jim Jarmusch, un de corto de David Lynch y se inicia con un "top ten" de escenas del cine que no serían lo mismo sin el café, como bebida y espacio de interacción social, elaborados por prestigiosos cineastas de la escena norteamericana.
\end{abstract}

Palabras clave: Café | Cine | Cineastas estadounidenses | Jim Jarmusch | David Lynch | Posmodernidad

Representations, meanings and senses when tasting a cup of coffee on the big screen

\begin{abstract}
This article arises from the spell of the combination between coffee and the seventh art, this document tries to think about the different representations, meanings and senses that arise after observing the mysterious dark drink projected on the big screen. In order to inhale the deep aroma of coffee, a mythical feature film by Jim Jarmusch is carefully reviewed, plus an analysis of a short film by David Lynch, and begins with a "top ten" (10) of movie scenes that would not be the same without the Coffee, as a drink and space for social interaction, prepared by prestigious filmmakers of the American scene.
\end{abstract}

Keywords: Coffee | Cinema | American Filmmakers | Jim Jarmusch | David Lynch | Postmodernity

\section{Introducción}

El presente artículo surge del hechizo que la combinación de cafeína, café y el séptimo arte ejerce sobre los protagonistas, pero también de notar que faltan textos profundos y de una extensión adecuada respecto a la relación entre el café, como bebida, y los cafés y cafeterías, como espacios de interacción social, en el terreno del séptimo arte.

El objetivo de estas líneas es analizar las diferentes representaciones, significados y sentidos que surgen tras observar a la misteriosa bebida oscura proyectadas en las pantallas. Por ello, se inicia un top ten de escenas del cine que no serían lo mismo sin el café, como bebida, y los cafés, como espacios de interacción social, elaborados por prestigiosos cineastas de la escena norteamericana, y se revisa con detenimiento un largometraje mítico de Jim Jarmusch, Coffee and Cigarettes, y What did Jack Do?, un cortometraje de David Lynch.

\section{Top 10: escenas y cafés}

El café como lugar y bebida es un referente recurrente en el cine. Esta inclusión se puede dar por dos razones: ayudar en la creación estética de un personaje o presen-

* Corresponding author: tesissandro@gmail.com 
tar un espacio común y cotidiano donde pueden pasar situaciones diversas que no son extrañas para el espectador. Es necesario recordar, como lo indica Bajtin (1982) que "El hombre en el arte es hombre integral" (p. 92), es decir, los protagonistas además de las acciones deben poseer una construcción externa, plástica, que genere un principio de realidad y haga que la ficción se haga cercana y creíble.

[...] Porque sólo en el arte la vida se representa: en el juego, la vida se imagina como los hemos anotado con anterioridad; la vida se vuelve representada tan sólo en la observación creativa del espectador. (Bajtin, 1982, p. 73)

Tanto en el cine como en la literatura, los personajes tienen diferentes atributos, externos e internos, pero tal vez son los elementos externos, descriptivos y visuales los que atrapan al público por su contundente expresividad comunicativa y su capacidad de generar empatía y familiaridad, lo cual permite vivir lo ficcional como una realidad: "Está claro que la apariencia como un valor estético no aparece como un momento de mi autoconciencia sino que se sitúa sobre la frontera del mundo plástico y pintoresco" (Bajtin, 1982, p. 36), que sin duda deleita y atrae al espectador, el cual entra al cine ávido de una experiencia entretenida. Existen objetos, accesorios y vestuarios que completan al personaje y los hacen llamativos, agradables o aberrantes a la vista:

Pero siempre existe un equivalente emocional y volitivo de la apariencia del objeto, siempre está presente una voluntad emocional de una apariencia posible aunque no visualizable que la crea como valor artístico. Por eso debe ser reconocido el valor plástico pictórico. (Bajtin, 1982, p. 88)

El objeto, la apariencia, y los contextos permiten materializar lo intangible de las emociones, el estado de ánimo, los pensamientos, y hasta el inconsciente del mismo sujeto; es decir, uno se alimenta del otro, y por esto es relevante su correspondencia para la construcción de un todo. En esta ocasión, el café es el objeto estético que se vuelve un atributo de la personalidad del protagonista, ya sea como un espacio o como una bebida recurrente del personaje; en ambos casos es un elemento que desarrolla la historia. Es necesario aclarar un principio de realidad en el caso de las personas que toman café, por lo general lo beben en grandes cantidades o muchas veces al día y de manera ritual, en otras palabras, con frecuencia y a ciertas horas, es por esta razón que aparece de forma repetida en las acciones de los personajes y es un lugar común, porque es una práctica cotidiana. A continuación, escenas que explican la relación entre un café y el desarrollo del personaje:
1. Pulp Fiction (Tarantino, 1994), director Quentin Tarantino: Jimmie Dimmick está en su casa con Vincent y Jules bebiendo un café gourmet. Jules alaba la bebida, y Jimmie afirma que compra un buen café porque le gusta su sabor. Sin embargo, esta taza de café es también el detonante de una discusión entre Jimmie y Jules, ya que el primero le hace ver una terrible situación: la esposa de Jimmie va a llegar, y lo encontrará con un cadáver en el garaje y unos gángsters cubiertos de sangre en la cocina. El delicioso café cambia de lo trivial a lo trágico, Jules no está de visita, trae graves problemas y Jimmie se lo deja claro al no aceptar su indiferencia y evasión con sus comentarios sobre la bebida. Además, esta escena muestra la vida hogareña de Jimmie, quien usa sus días para trabajar, estar con su esposa y permitirse una pequeña bendición propia de la vida en los suburbios: un café gourmet para despertar, no un instantáneo.

2. The usual suspects (Singer, 1995), director Bryan Singer: los policías, inspectores y detectives en el cine siempre toman café, puesto que deben trabajar en la noche y permanecer despiertos, el café les ayuda a estar alerta en sus oficinas y en las calles, y también es una bebida apreciada para estos personajes, es decir, la toman con placer. En esta película cuando el inspector Kujan descubre quién es el cerebro criminal -el cual se mantiene en secreto durante todo el film- se demuestra a través de la caída de una taza de café que él bebe casi durante toda la película (desarrollada en planos extensos y lentos). Kujan deja caer su taza llena de café al darse cuenta del error cometido y su estupidez para reconocer al criminal, observa la oficina y queda paralizado. Cuando por fin cae la taza y se rompe, Kujan sale de su parálisis e intenta atrapar al tullido, aunque ya es demasiado tarde. La destrucción de la taza se presenta aquí como una metáfora visual del error del inspector, de su descubrimiento y pérdida contra el crimen.

3. Bruce Almighty (Shadyac, 2003), director Tom Shadyac: Bruce es un hombre que recibe los dones de Dios. En esta escena él debe trabajar y responder plegarias. Al iniciar su día, Bruce para despertar bien y realizar su extensa labor, desea que aparezca un café... y aparece. Pero no se trata de cualquier café, él ahora es un ser supremo (aunque de gustos terrenales), así que es el mismo Juan Valdéz quien trae en una jarra su fresco café de montaña, aquí hasta "Dios toma un tinto" para comenzar su mañana como todo trabajador, pero esta vez es un buen café, en otra palabras, no es el simple café mortal que 
Bruce tomaba antes, en su casa o trabajo. Un buen café o un café costoso para el hombre promedio es un gusto que de vez en cuando se permite o que resalta cierto status social, al mismo tiempo indica que en el afán de la vida diaria el café es necesario, común y de diversos precios. El café como bebida aparece como ritual en la vida de los protagonistas que lo toman en las mañanas, pero también se vincula a la vida laboral del oficinista, detective, obrero: un café para iniciar la jornada. En otras ocasiones, una taza de café puede servir para mantener una buena conversación, dar consejos hacer una exhortación o una confesión, es una práctica que motiva encuentros: "Desde el punto de vista de la plasticidad artística, el mundo de la ilusión es un todo semejante al mundo de la percepción real" (Bajtin, 1982, p. 33), es por esto que en el cine también un café puede ser la excusa para la interacción entre los protagonistas, permite su conexión y, por lo tanto, el desarrollo de la historia:

\section{Fight club (Fincher, 1999), director David Fin-} cher: esta película inicia con el monólogo del protagonista, quien afirma que sufre de insomnio y ello hace su vida insufrible. Las primeras imágenes centran al mismo personaje en su oficina, donde todos toman café en vasos grandes para soportar la jornada laboral, seguido de varios planos de vasos usados de Starbucks (tal vez por esta razón el personaje no logra dormir). Más adelante, empieza a asistir a las reuniones de apoyo donde siempre sirven café ya que es gratis para los participantes, dato que Marla, su coprotagonista, señala. El café se hace importante en la película, puesto que la primera vez que estos personajes charlan Marla sirve un vaso de café que se riega al ser confrontada en ese instante, ya que él le trata de farsante y turista entre los grupos de apoyo emocional o psicológico de los cuales ella va y viene sin recatos. La discusión finaliza cuando ella le confiesa que va a las reuniones por el café, y se inicia un vínculo entre ellos, ya que ambos son farsantes en estas reuniones.

\section{The water diviner (Crowe, 2014), director Rus-} sell Crowe: Aquí hay una escena donde Ayshe le explica al extranjero Joshua Connor que en Turquía se decide todo con un café: los negocios, matrimonios, temas familiares, etc. La escena prosigue con una explicación sobre la lectura de los pozos del café. Además, Ayshe afirma que cuando una mujer desea casarse sirve a su enamorado un café muy dulce, acción que se ejecuta sobre el final de la película, lo cual demuestra el amor de Ayshe por Joshua. Un café también aparece en el cine como un espacio don- de los protagonistas desarrollan una serie de acciones, por ejemplo:

6. La La Land (Chazelle, 2016), director Damien Chazelle: la escena final de la película revela a Mia, la protagonista, de espaldas ingresando a un café. Ella antes era mesera allí y atendía a las actrices famosas de los estudios, aunque esta vez ella es una actriz reconocida y con éxito que ahora vive su propio sueño; entrar a ese café en particular es una representación de sus logros.

7. Taxi driver (Scorsese, 1976), director Martin Scorsese: Travis, un taxista y veterano de guerra, insiste en encontrarse con mujeres en cafés. El protagonista se esfuerza en mostrarse como un hombre serio y correcto, aunque humilde, que puede mantener un diálogo atento con Betsy e Iris en diferentes momentos sin aprovecharse de ellas, y comer o tomar algo. Se lo muestra sentado frente a frente con las protagonistas, tomando un café de modo sobrio y correcto.

8. Midnight in Paris (Allen, 2011), director Woody Allen: Gil, un escritor que sufre bloqueo creativo, se encuentra en París. Con su belleza e historia, esta ciudad empieza a inspirarle, e incluso le provoca vívidas ilusiones. En diferentes momentos de la película, Gil se halla en cafés parisinos con grandes artistas que se reúnen para hablar y discutir.

9. Groundhog day (Ramis, 1993), director Harold Ramis: en esta película Phil (Bill Murray), el presentador del clima, descubre que está atrapado en el tiempo y decide siempre citar a sus compañeros en el café "Tip Top" para tomar el desayuno. Es desde allí que nacen todas sus aventuras. Una escena importante de la película es la que muestra a Phil luego de varios días haciendo su misma rutina. Él logra conocer a todos los personajes del café de manera profunda, como un Dios, omnipresente, porque conoce ya sus vidas por medio del encuentro repetido en el desayuno en este lugar.

10. Para finalizar este top ten, el cortometraje The Rounders (Chaplin, 1914) dirigido por Charles Chaplin donde Charlot y Fatty borrachos llegan al "Smith's Cafe" para escapar de sus esposas, y hacen diversas locuras en un espacio para gente acomodada; como siempre Chaplin presenta un personaje irreverente y crítico frente a las brechas sociales. Asimismo, en muchas de sus películas Chaplin hace diversas escenas donde juega 
con tazas de café antes de beberlas, un recurso estético de la coreografía y puesta en escena en el cine mudo.

\section{Bonustrack: Pokémon, detective Pikachu (Le-} tterman, 2019), director Rob Letterman: el adorable detective Pikachu es adicto al café, característico de estos personajes policiacos, en muchas escenas este protagonista toma muchas tazas de café para mantenerse activo, lúcido y para organizar sus ideas que lo ayudarán a resolver el misterio.

\section{La mejor combinación: café y cigarrillos}

Este apartado se centra en una película de episodios, conformada por un conjunto de cortometrajes elaborados en distintas décadas, que es realmente antológica y emblemática respecto a la relación, que puede ser sobresaltada e incluso explotada, entre el cine y la misteriosa bebida negra conocida como "Café". Esa cinta es Coffee and Cigarettes (Jarmusch, 2003) del siempre controversial, pero atrevido cineasta norteamericano Jim Jarmusch.

El famoso director, guionista, actor, productor y compositor estadounidense, originario de esa ciudad que hizo gozar la movida underground del punk, Akron (Ohio), va a gestar este proyecto (inicialmente nada ambicioso ni pretencioso) desde mediados de los años ' 80 , cuando aparece el primer cortometraje de Coffee and Cigarettes (Jarmusch, 1986). Allí se presenta al cómico italiano -en ese entonces nada reconocido- Roberto Benigni, y al homólogo estadounidense Steven Wright, actuales leyendas del mundo de la comedia de sus respectivos países de origen. En 1993, uno de estos cortos recibe la Palma de Oro del Festival de Cannes, y once años después Jarmusch rueda Coffee and Cigarettes, un conjunto de episodios que hace un homenaje a esta combinación (tomar un café, mientras fumas y hablas). El film apela a las conversaciones entre personajes que pasan de expresiones profundas sobre la existencia, a lo trivial. Se trata de diálogos cotidianos en cafés, pero vistas desde el extrañamiento, la reflexión y, en ocasiones, desde el absurdo.

Coffee and Cigarettes es una serie de cortometrajes sobrios presentados todos en blanco y negro. Se trata de historias desarrolladas en cafés por personas conocidas en el cine y la música, quienes mantienen siempre una conversación y desarrollan un conflicto de manera rápi- da. Además presenta unos hilos conductores (objetos estéticos) evidentes al público: café, cigarrillos y una mesa ajedrezada. En suma, todo se puede discutir en una mesa con una buena taza de café y un cigarrillo en la mano.

Antes de ir hacia al análisis de los cortometrajes, es necesario detener la mirada sobre cómo logra Jarmusch esa fotografía en blanco y negro depurada, estilizada, construida a través de los años. La respuesta tiene un nombre y apellido: Robby Müller (1940-2018). En el momento en que se escribe este texto pasan solo unos meses del fallecimiento de este enorme ícono de la dirección de fotografía cinematográfica, originario de las Antillas Neerlandesas. Manuel Lombardo (4 de julio de 2018), le dedica unas sentidas líneas en la separata cultural del Diario de Sevilla al neerlandés: "Ha fallecido hoy, a los 78 años en su casa de Ámsterdam, Robby Müller, uno de los grandes directores de fotografía del cine europeo, estrecho colaborador e imaginero de directores esenciales como Wim Wenders, Jim Jarmusch o Lars Von Trier”.

La referencia pone la intensidad en tres referentes mundiales del cine, uno alemán, otro danés y, por supuesto, el estadounidense Jarmusch. Müller trabajó codo a codo, entre otros, con estos grandes cineastas, y a Jarmusch vino a imprimirle su inconfundible blanco y negro, un manejo de la cámara hipercontrolado y una afición por el encuadre desplazado y el travelling que tanto fascinan al cineasta de Akron que ya despunta en el cine independiente americano desde mediados de los 80: Down by Law (Jarmusch, 1986), Mistery Train (Jarmusch, 1989), Dead Man (Jarmusch, 1996) o Ghost Dog: The way of Samurai (Jarmusch, 1999) desarrollan esa particular mirada extraña y reveladora para la esencia visual de unos relatos marginales (Lombardo, 4 de julio de 2018). Afectado ya por una enfermedad degenerativa, uno de los últimos trabajos acreditados de Müller es precisamente el cortometraje de Jarmusch titulado "Gemelos” e incorporado en el largometraje.

Pero, ¿Qué hace distinto este trabajo conjunto entre Robby Müller, Tom DiCillo, Frederick Elmes, Ellen Kuras y otros bajo la dirección de Jarmusch?, ¿Qué lo hace distinto de otros trabajos en blanco y negro?, ¿Qué gramática se esconde tras estos modos de grabación? Para evitar demasiados tecnicismos traemos a colación las palabras de Juan Murillo (2005):

[...] en Coffee \& Cigarettes se busca la máxima dramatización, la mayor cantidad de "peripecias" o alternativas que puedan llegar a tener lugar en una unidad espacio-temporal; en concreto, hay una enfrascada y hasta forzada necesidad de entretener, de descomprimir y catalizar una situación opresiva de por sí. (pp. 4-5) 
Traducido a otros términos, lo que nos propone el conjunto de 11 cortos independientes de Coffee and Cigarettes es una suerte de escape posmoderno al tedio de la existencia misma. Nutriéndolo hasta el exceso, al borde del atosigamiento de referencias musicales e íconos que parecen rellenar, por así decirlo, una existencia que se precipita hacia el vacío. La referenciación permanente al café y los cigarrillos, casi como único puente narrativo oficial entre los episodios, evoca la necesidad de ingerir sustancias como la cafeína y la nicotina como herramientas (muy necesarias en el universo jarmuschiano) para poder resistir la pesada carga del insomnio americano.

Ahora bien, aunque no intentamos sesgar toda la investigación hacia Jim Jarmusch sino a su forma de (re) presentar al Café, como una bebida universal que toma desde el más humilde hasta la persona más exitosa y adinerada (como Cate Blanchett en el segmento "Primas"), queremos cerrar este apartado con unas palabras importantes sobre el espíritu del quehacer del cineasta de Akron (Ohio). Es interesante, por decir lo menos, que la tesis doctoral de Raúl Martínez Torres nos indica una suerte de paradoja: Jim Jarmusch, entre más intenta alejarse de la posmodernidad más posmoderno resulta (2009, p. 20). No solo ello, es todo un «prototipo de artista posmoderno» y de paso ayuda a entender y definir la posmodernidad cinematográfica:

[...] Acercándose a territorios rara vez transitados por sus coetáneos (ya sea el neorrealismo italiano, la nouvelle vague francesa, el código de honor de los guerreros en el Japón medieval o la espiritualidad de los nativos americanos), Jarmusch enseña cómo sacar partido a estos significados culturales desde la forma de consumo propia de la posmodernidad: caótica, heteróclita, mestiza, superficial, bulímica, abierta e integradora. (Martínez-Torres, 2009, p. 20)

Consumo, posmodernidad y lo cotidiano, no es otra cosa que la vida lo que pasa por estos cortometrajes. Sin embargo, es relevante puntualizar qué significados cobra el café como bebida y lugar en estas historias:

- Los insomnes: en muchos de los cortometrajes que componen Coffee and Cigarettes los personajes hablan del impacto que tiene en su sistema el café, el cual les altera los nervios y los mantiene en un estado de alerta. Esta situación es evidente en "Strange to meet you" y "Delirium", ambas conversaciones presentan sujetos aturdidos, un poco alucinados y saturados. Todo este vapor etéreo, que suscitan los intercambios de "porción del tiempo" acompañados de una buena taza de café, tienen más sentido cuando reconocemos en Jarmusch que esta bebida consumida por miles de millones de personas alrededor del mundo se convierte en una suerte de compañía ideal para los insomnes americanos que habitan los rincones de su cinematografía (Ródenas-Cantero, 2009). Pero ¿por qué hablar de insomnes e insomnio en Norteamérica? Porque el cine de Jarmusch se erige (desde sus inicios) en un claro oasis frente a la difundida idea de convivir o aspirar a un "sueño americano", un sueño agotador que se mantiene gracias a largas horas de trabajo o que deprime ante la falta del éxito; en las dos formas altera el descanso y el café es la perfecta compañía para una mente que no deja de divagar. Tanto así, que en los diálogos de los ya mencionados cortos, los protagonistas expresan una valoración casi surreal del café, ellos afirman que incluso altera sus sueños, que les hace soñar rápido y luego, no recordar nada. La bebida perfecta para el agotado ser posmoderno que niega su propio descanso y se autoexplota. En "Champagne" incluso se muestra a un personaje cansado y nostálgico, quien se queda dormido en un descanso del trabajo, que es también un descanso del café y por esta razón, se le ve relajado y dormido.

- Incapacidad para comunicar: otra constante en los cortometrajes es que los personajes no logran mantener conversaciones exitosas, tanto el emisor como el receptor son malinterpretados, se muestran aislados, egocéntricos, discuten, y los diálogos están llenos de silencios incómodos, gestualidades e interrupciones. Todo ello revela que la comunicación es como un proceso aparatoso y precario, que se debate entre el azar y el retraimiento. Estos dos elementos hacen referencia a una perspectiva de crítica, política o ideológica, frente a la idea de que hay cada vez más control en las calles y en las vidas cotidianas, y que la tecnología propicia una mejor comunicación. Ante estas dos creencias difundidas por los mass media (híper)modernos, Jarmusch traza una raya gruesa y colorida al contemplar que la vida (o al menos en su universo cinematográfico) son gobernadas más por el azar y por una terrible 
incomunicación. A manera de sarcasmo, el director hace más evidente el distanciamiento cuanto los personajes hacen parte de una misma familia, lo cual se observa en los cortometrajes: "Twins", "No problem", "Cousins", "Jack shows Meg his tesla coil” y "Cousins?”. Entonces, las conversaciones cambian por paralelos o personajes que crecen mientras el otro decae y todo se mantiene distante, casi como rupturas hostiles, lo que se aprecia en: "Somewhere in California" y "Renée”. El café, los cigarrillos y la mesa ajedrezada resultan incómodos testigos de la reducción del ser urbano (pos)moderno a su soledad.

- Dilema: en los cortometrajes se hace una referencia visual y enunciada a la combinación del café con los cigarrillos, se expresa como una buena mezcla pero también nociva, de manera frecuente un personaje habla y explica las terribles consecuencias de este mal hábito, aunque sin mayor éxito porque los protagonistas continúan en su errático actuar. Es así como Iggy Pop en "Somewhere in California", saborea un cigarrillo y dice: "Cigarrillos y café, amigo. Esa si es una buena combinación" (Jarmusch, 1993 y 2003). Ante ello, de inmediato responde Tom Waits "Somos la generación de café y cigarrillos, si lo piensas" (Jarmusch, 1993 y 2003). Su cavilación se prolongará para hacer una distinción bien particular: " $¿ S$ Sabes lo que quiero decir? En los '40, era la generación de la tarta y el café". Encaja mejor una combinación nociva y autodestructiva como el café con cigarrillos (cafeína y nicotina) para la actualidad, también se une a esta conjetura la condición de autodestrucción del sujeto, quien se abandona y se descuida. Del mismo modo, en este apartado se puede señalar la supresión de la comida por café y cigarrillos, hace pensar que los personajes no ingieren nada diferente a lo ya mencionado porque nunca piden comida en los cafés, lo que se muestra en: “Those things'll kil ya” y "Renée”, el dilema se plantea: fumar o no fumar, comer o tomar un café, y la respuesta es ya conocida.

- Los cafés: Coffee and Cigarettes (Jarmusch, 2003) lleva al espectador a una gran cantidad de cafés, sirve en diversidad de tazas, mesas y presenta a fumadores utilizando una amplia gama de marcas de cigarrillos; los cafés como contexto se muestran desprolijos y en otros cortometrajes aparecen elegantes, pero siempre habitados por personajes solitarios, que van de paso y con un cierto aire de fracaso. El café, no se presenta como un espacio familiar, por el contrario es un lugar para sujetos solitarios, que ya sea por el azar o por una cita terminan en un encuentro.

What did Jack Do? Lynch, un mono y, nuevamente, café y cigarrillos

Por otro lado, el cortometraje titulado What did Jack Do? del reconocido cineasta norteamericano y estandarte del surrealismo cinematográfico, David Lynch, presenta una producción de Absurda productions en colaboración la Fondation Cartier pour l'art contemporain (Lynch, 2020) donde se exhibe un diálogo entre David Lynch y un mono, sí, un mono que responde al nombre de Jack. El punto de encuentro donde se desarrolla la acción es en una estación de tren.

En los primeros minutos se observa a Lynch interrogar de una manera un tanto ruda al mono Jack. La imagen del mono, que en gran parte del cortometraje la presenta en un primer plano, está saturada de efectos, entre ellos un granulado artificial hecho por computadora y unos labios superpuestos (extirpando los naturales del animal) para revestirlo de mecanismos antropomórficos, claramente contra natura, pero que dentro del esquema surrealista suelen ser bienvenidos para que los sueños se puedan expresar: "Te han visto con gallinas, te juntas con gallinas" -acusa David Lynch a Jack-. "Háblame de Toototabon", insta Lynch bajo un plano pecho que mantiene a lo largo del metraje, pero Jack le sale con una de las tantas evasivas que copan el cortometraje. Nadie quiere ser interrogado, ni siquiera un mono.

Acto seguido, aparece una camarera sin dar previo aviso y les entrega un par de tazas de café. Ella se excusa por la demora, pero es que hay mucha gente hambrienta y policías en el tren. El mono Jack le dice que se quede con el cambio (aunque no se muestra dinero en ningún momento). Cada vez más irritado resulta el tono que le va imprimiendo Lynch al interrogatorio. Es ahí, cuando lanza esta bomba: "¿Eres o has sido miembro del Partido Comunista?”. Cerca del final del minuto 5 de este cortometraje pregunta Lynch a Jack: “ ¿Vas a beber el 
café?". Cuando eso ocurre hacen una cuidadosa toma de plano detalle (primer plano desde la perspectiva del objeto) y se nota la espuma y tranquilidad que emana de la bebida negra.

Un momento curioso resulta cuando menciona Lynch la ciudad de Bristol (se desconoce si es de Estados Unidos, Costa Rica, o Reino Unido), ya que el mono Jack muy ofendido le responde: "Nunca vuelvas a mencionarme ese lugar... No tienes ni un poco de decencia". Cerca del minuto 8 David Lynch enciende un fósforo para prender un cigarrillo (de nuevo aquí la combinación mágica de café y cigarrillos Jarmuschiana). El humo se disipa como en una película de cine negro norteamericano de los 40 . Toototabon era una gallina y es el primer amor de Jack.

En el minuto 13 cambia el tipo de plano para el mono: pasa a un plano medio, lo que brinda una perspectiva de crecimiento del personaje. También se aprecia una parte (izquierda) de la taza de café con su respectiva oreja (mango). Sobre el final del minuto 14 aparece la nombrada gallina Toototabon. Jack, al verla, la llama de forma desesperada, pero cual gallina sale corriendo sin dirección fija. Tras ella, sale a perseguirla Jack. Ahora, se utiliza los clarososcuros bajo un método propio de los expresionistas alemanes de viejo cuño, sale David Lynch para arrestar a Jack, acusado del asesinato de Max Clegg. Aunque esa parte del arresto no la aprecia el cinevidente, se apela a la estrategia del fuera de campo para aumentar la tensión.

En este cortometraje, el rol del café consiste en generar una ruptura en la "armonía" del diálogo entre Lynch y Jack. Asimismo, da oportunidad a que un tercer personaje emerja: la mujer (aquí como una camarera) pero que viene a aportar la dulzura que no se halla en el interrogatorio que Lynch sostiene con el mono y es quien anuncia el misterio: "un asesino suelto en el tren". A ninguno de los dos se les ve tomando la taza de café, aunque sí prendiendo un cigarrillo. Hay canto, amor, tragedia... un mono asesino interrogado por Lynch, todo esto como salido de una pesadilla. El café emerge como un factor normalizador (la taza y la bebida fusionadas como un único producto) que permite cierta sana distracción al cinevidente del denso y extraño diálogo sostenido por los protagonistas. Una vez más, el café como motivo de encuentro y un elemento que permite el desarrollo de un diálogo y la evolución de un conflicto, así sea en una situación de ensoñación, acá el café es el objeto estético que ordena la situación surreal y lo acerca a lo cotidiano.

\section{Conclusiones}

En un texto que toca el tema de la posmodernidad como este, repleto de referencias, algunas de ellas incluso antagónicas como ocurre en la cotidianeidad y en el arte actual, lo ideal es que cada lector extrajera sus propias conclusiones. Sin embargo, para finalizar, se resalta que tal y como lo explica Bajtin (1982) en la búsqueda de construir personajes se debe materializar en un objeto de apariencia convencional toda una carga de significado emocional y psíquico para que se haga concreto, como una taza de café por ejemplo, que demuestra la fuerza estética de la representación y la carga simbólica (e incluso onírica como en el cine de David Lynch), y que puede sugerir a un cinevidente promedio una familiarización y una repetición constante de un hábito difundido -no solo en el espacio norteamericano- sino que se torna universal como lo es tomar café.

Por último, es importante resaltar que toda esta lista de escenas o cortometrajes que incluyen un café son solo una excusa para señalar la aparición y los diferentes significados que un mismo elemento puede llegar a tener por su recurrencia, como bebida, objeto que permite el encuentro, hábito del personaje y de los espacios como las cafeterías y cafés en el mundo cinematográfico. El café, sin duda, seguirá presente en el cine y vigente en la sociedad de consumo y la vida laboral, incluso apunta hacia la idea que una taza de café puede ser una bebida universal. Un dato nada menor es que el mundo de la imagen en movimiento surge precisamente un 28 de Diciembre de 1895, en el salón "Indien du Grand Café" de París, a cargo de los legendarios hermanos Lumière: Louis y Auguste. Es como si el mundo del séptimo arte estuviese condenado, desde sus inicios, a tener una relación con el café y las cafeterías. Ante esto ¿qué hacer? ¿Rendirse o luchar contra un café, un cigarrillo y una conversación?

\section{Agradecimientos}

Los autores agradecen al cine-club cinErrantE por sus 12 años de un caminar constante difundiendo el gusto por el séptimo arte y al grupo de investigación HARED de la Universidad Industrial de Santander (UIS, Bucaramanga), que ha dado cabida desde hace 9 años a líneas de investigación ligadas a la historia del cine y la apreciación cinematográfica. Asimismo, al espacio de Cineurosis que ha sido posible gracias al apoyo de la Universidad Cooperativa de Colombia (UCC, Barrancabermeja). 


\section{Referencias}

Albert, T., Ramis, H. (productores) y Ramis, H. (director). (1993). Groundhog Day [Cinta cinematográfica]. Estados Unidos: Columbia Pictures.

Aronson, L., Tenenbaum, S., Roures, J. (productores) y Allen, W. (director). (2011). Midnight in Paris [Cinta cinematográfica]. Estados Unidos: Mediapro.

Bajtin, M. M. (1982). Estética de la creación verbal. Madrid, España: Siglo XXI Editores.

Bender, L., Devito, D. (productores) y Tarantino, Q. (director). (1994). Pulp Fiction [Cinta cinematográfica]. Estados Unidos: Miramax.

Berger, F., Gilbert, G., Horowitz, J., Platt, M. (productores) y Chazelle, D. (director). (2016). La La land [Cinta cinematográfica]. Estados Unidos: Summit Entertainment.

Grayson Bell, R., Chaffin, C., Linson, A. (productores) y Fincher, D. (director). (1999). Fight Club [Cinta cinematográfica]. Estados Unidos: Fox 2000 Pictures.

Jarmusch, J., Guay, R., Schmidt, D. (productores) y Jarmusch, J. (director). (1999). Ghost Dog: The way of Samurai [Cinta cinematográfica]. Estados Unidos: Pandora Filmproduktion.

Kleinberg, A., Rothman, T., Stark, J. (productores) y Jarmusch, J. (director). (1986). Down by Law [Cinta cinematográfica]. Estados Unidos: Black Snake.

Kliot, J., Simmons, R., Stark, J., Staudt, B., Vicente, J. (productores) y Jarmusch, J. (director). (2003). Coffee and Cigarettes [Cinta cinematográfica]. Estados Unidos: Asmik Ace Entertainment.

Lombardo, M. J. (4 de julio de 2018). Adiós a Robby Müller, maestro de la 'vagancia creativa'. Diario de Sevilla. Recuperado de https://www.diariodesevilla.es/ocio/Adios-Robby-Muller-vagancia-creativa_0_1260474613.html

Lum, T., Mason, A., Rodger, K. (productores) y Crowe, R. (director). (2014). The Water Diviner [Cinta cinematográfica]. Australia: Fear of God Films.

MacBride, D. J., Koch, K. (productores) y Jarmusch, J. (director). (1995). Dead Man [Cinta cinematográfica]. Estados Unidos: Pandora Filmproduktion.

MacBride, D. J., Staudt, C. B. (productores) y Jarmusch, J. (director). (1993). Coffee and Cigarettes III [Cinta cinematográfica]. Estados Unidos: Cinesthesia Productiones.

Martínez-Torres, R. (2009). Jim Jarmusch desde la posmodernidad (tesis doctoral). Universitat Ramon Llull, Barcelona, España.

Murillo, J. E. (2005). Coffee and Cigarettes. La conjura de los trasnochados. Santiago de Chile, Chile: laFuga. Recuperado de http://2016.lafuga.cl/coffee-cigarrettes/155

Parent, M., Boyter, C. (productores) y Letterman, R. (director). (2019). Pokémon Detective Pikachu [Cinta cinematográfica]. Estados Unidos: Warner Bros.

Phillips, J., Phillips, M. (productores) y Scorsese, M. (director). (1976). Taxi Driver [Cinta cinematográfica]. Estados Unidos: Columbia Pictures.

Ródenas-Cantero, G. (2009). Jim Jarmush. Lecturas sobre el insomnio Americano (1980-1991) (Tesis doctoral). Universidad de Murcia, Murcia, España.

Sennett, M. (productor) y Chaplin, Ch. (director). (1914). The Rounders [Cinta cinematográfica]. Estados Unidos: Keystone Film Company.

Shadyac, T., Carrey, J., Brubaker, J., Bostick, M., Koren, S., O’Keefe, M. (productores) y Shadyac, T. (director). (2003). Bruce Almighty [Cinta cinematográfica]. Estados Unidos: Spyglass Entertainment.

Simmons, R., Stark, J. (productores) y Jarmusch, J. (director). (1989). Coffee and Cigarettes II [Cinta cinematográfica]. Estados Unidos: Black Snake.

Singer, B. (productor) y Singer, B. (director). (1995). The usual suspects [Cinta cinematográfica]. Estados Unidos: PolyGram Filmed Entertainment.

Stark, J. (productor) y Jarmusch, J. (director). (1986). Coffee and Cigarettes [Cinta cinematográfica]. Estados Unidos: Cinesthesia Productiones.

Stark, J., MacBride, D. J. (productores) y Jarmusch, J. (director). (1989). Mistery Train [Cinta cinematográfica]. Estados Unidos: JVC Entertainment Networks.

Sutherland, S. (productor) y Lynch, D. (director). (2015). What did Jack do? [Cinta cinematográfica]. Estados Unidos: Netflix. 